Article

\title{
Rheological Behavior and Sensitivity of Wood-Derived Bio-Oil Modified Asphalt Binders
}

\author{
Junfeng Gao ${ }^{1,2} \mathbb{E}^{\mathbb{D}}$, Hainian Wang ${ }^{1, *}$, Zhanping You ${ }^{2, *} \mathbb{C l}^{\circ}$, Mohd Rosli Mohd Hasan ${ }^{3}$, \\ Yong Lei ${ }^{1}$ (i) and Muhammad Irfan 4 (iD) \\ 1 South Erhuan Middle Section, Chang'an University, School of Highway, Xi'an 710064, China; \\ gaojunfeng@chd.edu.cn (J.G.); leiyong@chd.edu.cn (Y.L.) \\ 2 Department of Civil and Environmental Engineering, Michigan Technological University, 1400 Townsend \\ Drive, Houghton, MI 49931, USA \\ 3 School of Civil Engineering, Universiti Sains Malaysia, Engineering Campus, Nibong Tebal, \\ Pulau Pinang 14300, Malaysia; cerosli@usm.my \\ 4 College of Civil Engineering, National University of Sciences and Technology (NUST) NUST Campus, \\ Risalpur 24080, Pakistan; mirfan@mce.nust.edu.pk \\ * Correspondence: wanghainian@aliyun.com (H.W.); zyou@mtu.edu (Z.Y.)
}

Received: 21 April 2018; Accepted: 30 May 2018; Published: 3 June 2018

Featured Application: This study of rheological behavior and sensitivity of wood-derived bio-oil modified asphalt binders would lay a foundation for the performance research and further engineering practice of bio-asphalt binders.

\begin{abstract}
The demand for bituminous materials is continuously growing; crude oil-based asphalt binders are non-renewable, and are facing rapid depletion. With the increase of petroleum-based asphalt prices, seeking an alternative, renewable material such as bio-asphalt has become a hot research topic. However, shortcomings in this research area have been identified, notably concerning the high-temperature performance of bio-asphalt at present. This research aims to comprehensively apply conventional tests to, and study the rheological behavior of, the high-temperature performances of bio-asphalt binders, i.e., by temperature and frequency sweeps, using a dynamic shear rheometer (DSR). It will also assess the chemical functional groups of specimens prepared by different aging conditions. Fifty penetration grade base asphalt binder (50\#), bio-oil modified asphalt binders with $0 \%, 5 \%, 10 \%$, and $30 \%$ bio-oil contents by mass, and bio-oil modified asphalt binder with combinations of $5 \%$ bio-oil- $1 \%$ SBS, and $10 \%$ bio-oil- $1 \%$ SBS were used in this study. The conventional performance of bio-asphalt binders was tested using penetration, ductility, and softening point, before and after short-term aging conditioning. The temperature sweep and frequency sweep of bio-asphalt under different bio-oil contents were carried out via DSR. Two-logarithmic equations of rutting factor and temperature were established, and the temperature sensitivity of bio-asphalt was analyzed. The master curves of virgin asphalt and bio-asphalt were constructed at $64{ }^{\circ} \mathrm{C}$. The results indicate that the incorporation of bio-oil reduced the anti-rutting performance of asphalt, and the bio-oil content had a significant effect on the mass loss of the bio-asphalt binder. The performance of bio-oil modified asphalt binders using 5\% bio-oil, 5\% bio-oil- $1 \%$ SBS, and $10 \%$ bio-oil- $1 \%$ SBS, could meet the requirements of 50\# grade asphalt. The temperature sensitivity of bio-asphalt did not show obvious change before and after short-term aging, whereas the temperature sensitivity of bio-asphalt with $5 \%$ bio-oil was relatively small. With an increase in temperature, the phase angle increased gradually. In contrast, the storage modulus, loss modulus, and complex modulus decreased progressively. The complex modulus and rutting factor of bio-asphalt with $5 \%$ bio-oil steadily increased with the increase in testing frequency. Otherwise, chemical reactions were detected in the 50\# base asphalt modified with the bio-oil.
\end{abstract}


Keywords: road engineering; bio-oil; asphalt binder; high-temperature performance; master curve

\section{Introduction}

Nowadays, the binding agent for road materials is mainly petroleum asphalt extracted from the fossil fuel. With the gradual reduction of oil reserves, oil prices are rising, which results in a higher cost of bitumen. With the growing demand for asphalt, the construction and maintenance costs of highways have also escalated. Therefore, the performance of traditional asphalt must be improved, and the need for alternatives is great [1-3]. Biomass energy has a wide range of sources, large yields, and low prices. In recent years, a significant number of researchers have turned their attention to bio-oil extracted from biomasses by high-temperature pyrolysis [4-6].

Many researchers mainly use bio-oil as an additive to modify the base binder. However, most were only focused on the performance of bio-asphalt containing a mixture of base binder and bio-oil. Fini et al. [7-11] modified petroleum asphalt with $2 \%, 5 \%$, and $10 \%$ bio-oil by mass of the asphalt binder. Bio-oil was extracted from pig manure through a process of pyrolysis. Bio-oil modified binders were tested for high-temperature viscosity, and the low and high temperature rheological behavior was examined using a rotational viscometer (RV), a dynamic shear rheometer (DSR), and a bending beam rheometer (BBR). Mills-Beale et al. [12] tested 5\% bio-oil extracted from pig manure to modify petroleum asphalt PG 64-22; performance was tested by RV, DSR, and BBR, before and after short-term aging. Raouf et al. $[13,14]$ obtained bio-oil from oak wood, and pretreated it for $2 \mathrm{~h}$, then mixed $2 \%$ and $4 \%$ dosages of polyethylene to modify it. They then determined the viscosity within a temperature range of $40 \sim 160{ }^{\circ} \mathrm{C}$, and analyzed the effect of temperatures on viscosity. Tang et al. [15] applied three types of bio-oil extracted from corn stalks, oak trees, and shredded grass, to modify base asphalt and SBS modified asphalt. The dosages of each bio-oil were 3\%, $6 \%$, and $9 \%$, based on binder mass. The high temperature performances of bio-asphalt before and after short-term aging were then tested, and the anti-aging properties were analyzed. Yang et al. [16] tested high-temperature viscosity, density, and the rheological properties of bio-asphalt with different contents of bio-oil extracted from cedar sawdust. The $25 \%$ and $50 \%$ bio-oils were utilized to replace part of the AC-20 base binder, while the $2 \%$ and $8 \%$ bio-oil were used for the modification of a similar binder. Wang, Gao et al. [17-19] summarized and compared the bio-oil production procedure and fabrication process of bio-asphalt. They then analyzed the performance and characterization of different bio-binders. They also studied variations in viscosity at different temperatures and with different contents of bio-oil. The results showed that the viscosity of the bio-binder decreased with an increase in the content of bio-oil when the test temperature was under $135^{\circ} \mathrm{C}$. He et al. [20] investigated the conventional performances of bio-asphalt by penetration, softening point, and ductility. The test results indicated that, using a mixture of bio-oil and modified asphalt, the penetration declined with an increase in the proportion of modified asphalt, and ductility improved greatly, which corrected with the disadvantages of hard and brittle bio-asphalts at low temperatures.

At present, the research of bio-asphalt mainly focuses on the binder materials, and tests mainly focus on the conventional indexes of the binder materials; such studies lack systematic analysis. The study of bio-asphalts at different frequencies is also rarely reported. In this study, bio-oil was extracted from wood chips, and a bio-asphalt binder was prepared with petroleum asphalt with different contents of bio-oil. The conventional performance indexes of the bio-asphalt binder were tested. The temperature and frequency sweep tests of bio-asphalt with different bio-oil contents were carried out by DSR. The two-logarithmic equations, rutting factor and temperature, were established, and the temperature sensitivity of bio-asphalt was analyzed. The master curves of the asphalt and bio-asphalt matrix were recorded at $64^{\circ} \mathrm{C}$; this was selected as the reference temperature. Changes of complex modulus and rutting factors of bio-asphalt under different loading frequencies were studied. This study may provide important fundamental information for the further study of 
the high-temperature performance of bio-asphalt binders and the selection of evaluation indices, and would lay the foundation for the further engineering applications of bio-asphalts.

\section{Objective}

The specific objectives of this study are as follows:

(1) To develop a new, environmentally friendly, and sustainable asphalt material for road engineering.

(2) To systematically study the high-temperature performance of bio-asphalt binders.

(3) To determine the changes of complex modulus and rutting factors of bio-asphalts at a wide range of loading frequencies.

The experimental plan followed in this study is shown in Figure 1.

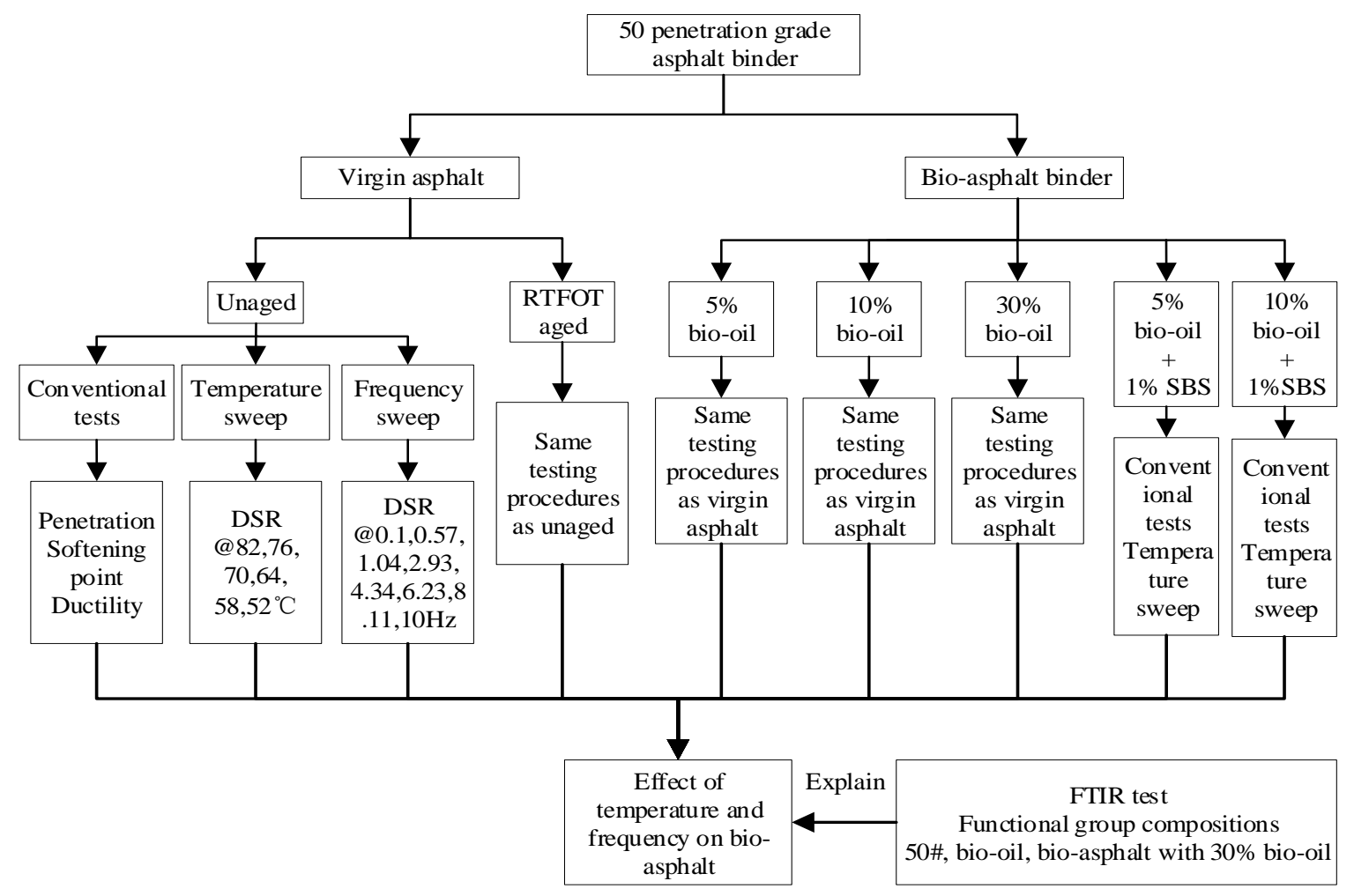

Figure 1. Experimental design map.

\section{Materials and Test Program}

\subsection{Materials and Preparation of Bio-Asphalt Binder}

\subsubsection{Materials}

Fifty-penetration grade asphalt (hereafter referred to as 50\#) produced by Sinopec Group Maoming Petrochemical Company, Mao Ming, China, was selected as the base asphalt binder. Bio-oil was provided by Toroyal New Energy Company, Dongying, China; it was extracted from wood chip, and is dark brown in color and shows plasticity at room temperature, with a certain mobility at a higher temperatures. The density of the bio-oil is $1.1 \mathrm{~g} / \mathrm{cm}^{3}$, and the $\mathrm{pH}$ is 2.6 . Its elemental composition is: $54-56 \% \mathrm{C}, 35-45 \% \mathrm{O}, 5.5-7.2 \% \mathrm{H}$, and $0-0.2 \% \mathrm{~N}$. The bio-oil is shown in Figure 2. The SBS additive is produced by Yuehua Company, Yueyang, China; it has a 1301-1 linear structure. 


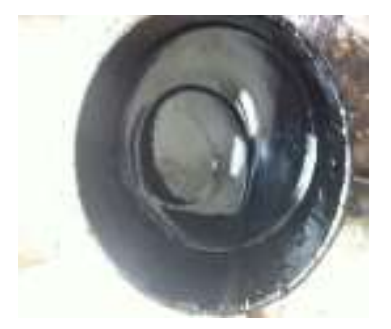

Figure 2. Bio-oil derived from the wood chip.

\subsubsection{Preparation of Bio-Asphalt Binders}

A preparation program was determined according to a previous study [19] and former tests. Asphalt binders with bio-oil/ SBS additives were prepared by different processes.

Asphalt binder with bio-oil: The 50\# grade matrix asphalt was heated to 140 to $145^{\circ} \mathrm{C}$. Different contents of bio-oil were added to the base asphalt. The contents of the bio-oil were $5 \%, 10 \%$, and 30\% of the total binder by weight. The base binder and bio-oil were mixed with a high shear mixer for $20 \mathrm{~min}$, with a rotation speed of $5000 \mathrm{r} / \mathrm{min}$.

Asphalt binder with SBS additive and bio-oil: The 50\# grade matrix asphalt and SBS were mixed at $180^{\circ} \mathrm{C}$ through a high-speed shear machine for $15 \mathrm{~min}$. Then, the bio-oil was added to the mixed binders, and mixed for $20 \mathrm{~min}$; the temperature was kept at $140 \sim 145^{\circ} \mathrm{C}$. The speed of the shear machine was $3000 \mathrm{r} / \mathrm{min}$ [21]. A 1\% content by of SBS total binder by weight was selected. Bio-oil contents were $5 \%$ and $10 \%$ of the total binder by weight, and the prepared bio-asphalt with SBS additive were named $5 \%$-S and 10\%-S.

The asphalt binder with bio-oil, and the asphalt binder with SBS additive and bio-oil were both named bio-asphalt binder.

\subsection{Test methods and Master Curve Generation Method}

\subsubsection{Conventional Test Method}

Conventional tests of the prepared bio-asphalt binders were carried out, including penetration, softening point, and ductility, before and after Rolling Thin Film Oven (RTFO) aging, and mass loss. The tests were conducted based on the Standard Test Methods of Bitumen and Bituminous Mixtures for Highway Engineering (JTG E20-2011).

\subsubsection{Temperature Sweep Test Method}

The temperature sweep of the bio-asphalt binders with 5\%, 10\%, and 30\% bio-oil, and 5\%-S, 10\%-S, before and after Rolling Thin Film Oven (RTFO) aging, was carried out using a dynamic shear rheometer DHR-1, manufactured by the TA Company. Continuous sinusoidal alternating load and strain control mode were selected; the strains were $12 \%$ and $10 \%$ before and after RTFO. The temperature sweep range was $52 \sim 82{ }^{\circ} \mathrm{C}$; the interval was $6{ }^{\circ} \mathrm{C}$. Test frequency was $1.59 \mathrm{~Hz}$. The diameter of the asphalt sample fixture was $25 \mathrm{~mm}$, while the test spacing of asphalt sample was $1 \mathrm{~mm}$. The complex shear modulus $G^{*}$, phase angle $\delta$, and the rutting factors $G^{*} / \sin \delta$ of the bio-asphalt binder, were measured and analyzed.

\subsubsection{Frequency Sweep Test Method}

After conventional tests and temperature sweep, the matrix asphalt and the selected bio-asphalt were subjected to a frequency sweep test. The test conditions, including strain control mode, the diameter of asphalt sample fixture, the test spacing of asphalt sample, were the same as those of the temperature sweep test. Temperature range for the frequency sweep was $40 \sim 76^{\circ} \mathrm{C}$; the interval 
was $6{ }^{\circ} \mathrm{C}$. Test frequencies were $0.1 \mathrm{~Hz}, 0.57 \mathrm{~Hz}, 1.04 \mathrm{~Hz}, 2.93 \mathrm{~Hz}, 4.34 \mathrm{~Hz}, 6.23 \mathrm{~Hz}, 8.11 \mathrm{~Hz}$, and $10 \mathrm{~Hz}$, respectively.

\subsubsection{Master Curve Generation Method}

The viscoelasticity of viscoelastic materials has a certain dependence on temperature and loading frequency. At different temperatures and frequencies of action, the viscoelastic materials might exhibit the same mechanical behaviors, that is, the effects of time and temperature on the viscoelastic material are equivalent. The viscoelastic curve obtained at different temperatures could be converted into the viscoelastic master curve at the reference temperature through the time-temperature equivalent principle; in this way, the scanning results could be extended to the broadband range.

In this paper, a sigmoidal function was used to construct the master curve of complex modulus and rutting factor, by means of Excel solver; the formula is shown in Equation (1).

$$
\log (A)=\delta+\frac{\alpha}{1+e^{\beta-\gamma \log (\xi)}}
$$

where $A$ is complex modulus or rutting factors, which is the minimum value of complex modulus or rutting factor, $\delta$ is the reduced frequency at the reference temperature, $\alpha$ is the difference between the maximum and minimum values of complex modulus or rutting factor, and $\beta, \gamma$ are the shape parameters.

\subsubsection{Fourier-Transform Infrared Spectroscopy}

The Fourier-transform infrared spectroscopy (FTIR) is a machine used to determine the spectroscopy; it is widely used to analyze the chemical functional groups of asphalt materials. The TENSOR27, produced by the Bruker Optics Company, was used to research the asphalts and bio-asphalts in this study. The resolution was $4 \mathrm{~cm}^{-1}$, the scanning speed was 32 sheets per second, and the selected scanning range was $4000 \sim 600 \mathrm{~cm}^{-1}$. The functional groups were identified and compared for further analysis.

\section{Results and Discussion}

\subsection{Conventional Tests}

The results of conventional performance indicators of bio-asphalt binders with $5 \%, 10 \%$, and 30\% bio-oil, and 5\%-S, 10\%-S, were analyzed.

The penetration ratio and residual penetration ratio of unaged and RTFO-aged bio-asphalt are shown in Figure 3. For the unaged bio-asphalt, with an increase of bio-oil content, the penetration of bio-asphalt increases. This showed that, with the incorporation of bio-oil, asphalt became soft; its high temperature performance was reduced to some extent. Meanwhile, the penetration of 5\%-S and 10\%-S were decreased by $5 \%$ and $10 \%$ respectively, due to the incorporation of SBS. Compared with the matrix asphalt 50\#, the penetration increments of unaged bio-asphalt with $5 \%, 10 \%$, and $30 \%$ bio-oil were $5 \%$, $12.3 \%$, and $79.2 \%$, respectively. This indicated that a higher bio-oil content produces a greater change in penetration. After short-term aging, the bio-asphalt became harder, and resistance to rutting increased for the RTFO-aged bio-asphalt. The change in the residual penetration ratio also illustrated this point. Compared with RTFO aged bio-asphalt with $5 \%$ and $10 \%$ content bio-oil, the penetration of RTFO-aged bio-asphalt with $30 \%$ bio-oil was much smaller, and the residual penetration ratio was $36.73 \%$. This was due to the effects of the volatility of the light components of bio-oil during RTFO aging. An increase in bio-oil content would lead to an increase in the aging and variability of bio-asphalt. The residual penetration ratio of bio-asphalt with 5\% content bio-oil and 5\%-S, $10 \%$-S could meet the requirements of 50\# asphalt binder, as outlined in Technical Specifications for Construction of Highway Asphalt Pavements (JTG F40-2004). However, the residual penetration ratio of bio-asphalts with 10\% and 30\% content bio-oil would not meet the requirements. 


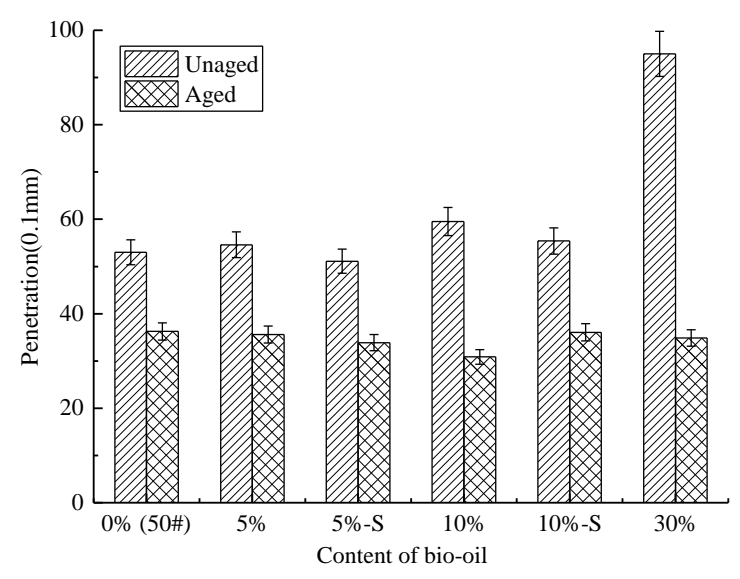

(a)

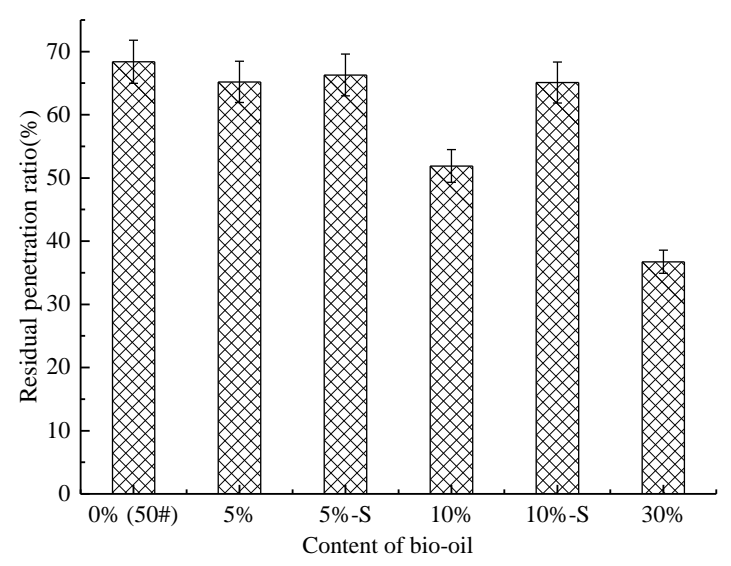

(b)

Figure 3. Penetration ratio and residual penetration ratio of unaged and RTFO (Rolling Thin Film Oven) aged bio-asphalt. (a) Penetration ratio; (b) Residual penetration ratio.

The softening points of unaged and RTFO-aged bio-asphalt are shown in Figure 4. The softening point of unaged bio-asphalt decreased with an increase of bio-oil content. This showed that, with the incorporation of bio-oil, the high temperature performance of bio-asphalt was reduced to some extent. Meanwhile, the addition of SBS could increase the softening point of bio-asphalt with $5 \%$ and $10 \%$ bio-oil. The softening point of RTFO-aged bio-asphalt increased with an increase of bio-oil content. This illustrated that, with the incorporation of bio-oil, the asphalt became harder, and the resistance to rutting is increased. The softening point of unaged and RTFO-aged 10\%-S increased more than that of $5 \%$ bio-oil. The incorporation of SBS could improve the high temperature performance of bio-asphalt. Compared with the original asphalt, the difference of the softening point of unaged and RTFO-aged bio-asphalts with $5 \%, 10 \%$, and $30 \%$ bio-oil content were $9.6{ }^{\circ} \mathrm{C}, 16.5{ }^{\circ} \mathrm{C}$, and $20.6{ }^{\circ} \mathrm{C}$, respectively. With an increase of bio-oil content, the softening point increased. This was caused by the aging of bio-asphalt, and indicated that with a greater amount of bio-oil, the aging degree of bio-asphalt increases. 


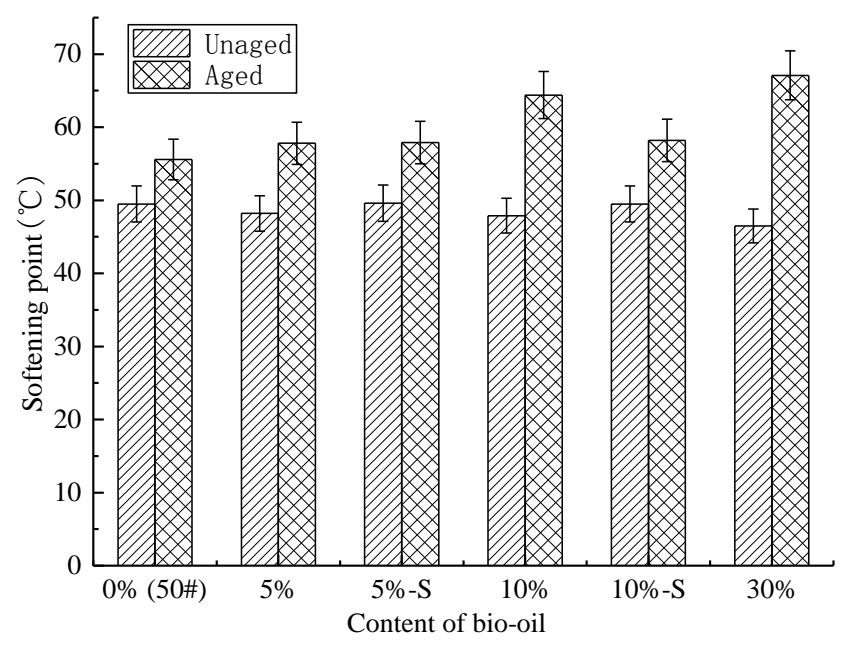

Figure 4. Softening point of unaged and RTFO aged bio-asphalt.

As seen in Figure 5, with the increase of bio-oil content, the ductility of unaged bio-asphalt increased. As compared with the base asphalt binder, the ductility of bio-asphalts with $5 \%, 10 \%$, and $30 \%$ bio-oil content increased by $2.6 \%, 8.7 \%$, and $52.8 \%$, respectively. This showed that the addition of bio-oil could improve the low temperature performance of bio-asphalt, and improve the low temperature, anti-cracking ability of asphalt before RTFO-aging. Meanwhile, the ductilities of 5\%-S and $10 \%-S$ were increased by $16.5 \%$ and $13.2 \%$, respectively, indicating that the incorporation of SBS would improve the low temperature properties of the bio-asphalt binder. Referring to the RTFO-aged bio-asphalt, with an increase in bio-oil content, ductility decreased, indicating that the asphalt became relatively hard after short-term aging. However, for $5 \%-\mathrm{S}$ and $10 \%-\mathrm{S}$, the ductility indicated that SBS could also improve the low temperature properties of RTFO-aged bio-asphalt binders.

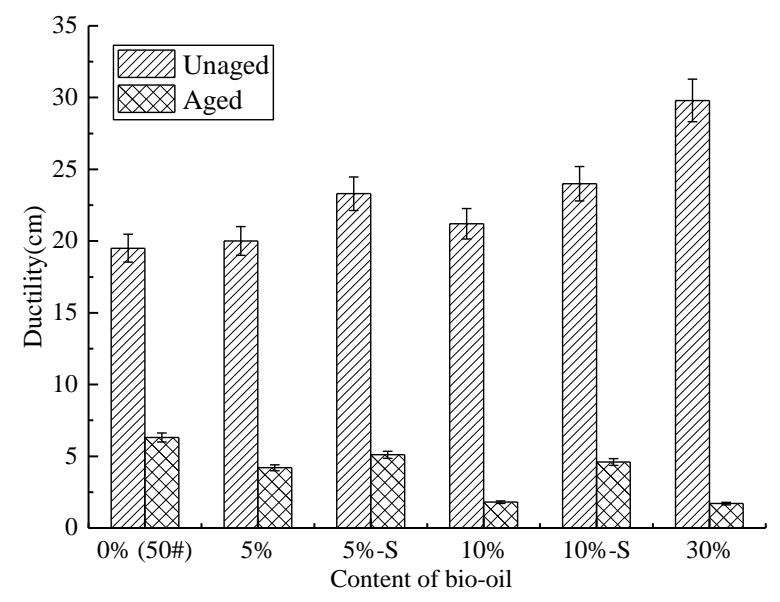

Figure 5. Ductility of unaged and RTFO aged bio-asphalt.

Mass losses between unaged and RTFO-aged bio-asphalt are shown in Figure 6. With the increase of bio-oil content, the mass loss of bio-asphalt increased. This showed that the addition of bio-oil made the mass of bio-asphalt decrease at $163^{\circ} \mathrm{C}$. This was due to the volatilization of light components, and the aging of the asphalt. Meanwhile, the greater the amount of bio-oil, the more aging occurred. However, for $5 \%-\mathrm{S}$ and $10 \%-\mathrm{S}$, the mass loss was lower than $5 \%$ and $10 \%$ of the bio-oil content, which means that the incorporation of SBS would decrease the aging of bio-asphalt. The mass loss of bio-asphalt with $5 \%$ bio-oil content was $-0.580 \%$, which could meet the requirements described in the Technical Specifications for Construction of Highway Asphalt Pavements (JTG F40-2004). The 5\%-S 
and $10 \%-\mathrm{S}$ could also meet these specifications. However, the mass loss of bio-asphalt with $10 \%$ and $30 \%$ content bio-oil would not meet the requirements.

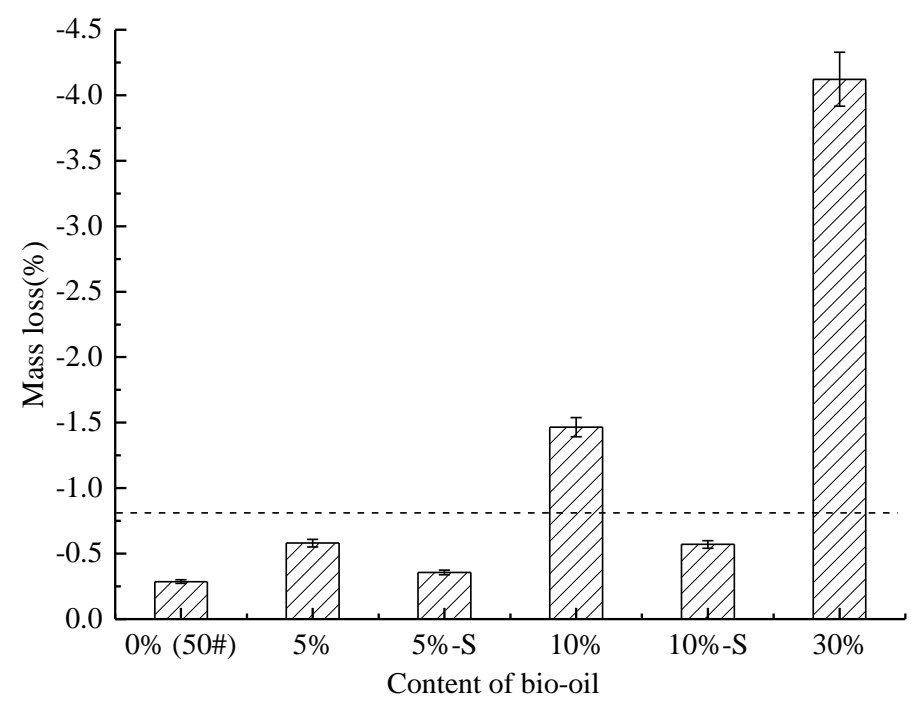

Figure 6. Mass loss between unaged and RTFO aged bio-asphalt.

It was found that the incorporation of bio-oil had a great influence on the mass loss of the bio-asphalt, but that the effect of different dosages was unknown. To identify the difference between the different types of asphalt, and to understand the significant changes in the mass of bio-asphalt with varying bio-oil contents, the LSD (Least Significant Difference) method was used. The LSD method is the most sensitive of the various multi-comparison methods. It is able to detect small differences between groups. The analysis through LSD of the effects of different bio-oil contents on mass loss is shown in Table 1.

Table 1. Analysis through LSD (Least Significant Difference) of the effects of different bio-oil contents on mass loss.

\begin{tabular}{|c|c|c|c|c|c|c|}
\hline \multirow{2}{*}{$\begin{array}{l}\text { Content of } \\
\text { Bio-Oil }\end{array}$} & \multirow{2}{*}{$\begin{array}{l}\text { Content of } \\
\text { Bio-Oil }\end{array}$} & \multirow{2}{*}{$\begin{array}{c}\text { Mean } \\
\text { Difference }\end{array}$} & \multirow{2}{*}{$\begin{array}{l}\text { Standard } \\
\text { Error }\end{array}$} & \multirow{2}{*}{ Significance } & \multicolumn{2}{|c|}{ 95\% Confidence Interval } \\
\hline & & & & & Lower Limit & Upper Limit \\
\hline \multirow{3}{*}{$0 \%$} & $5 \%$ & $-0.294000 *$ & 0.052726 & 0.001 & -0.41559 & -0.17241 \\
\hline & $10 \%$ & $-1.180000 *$ & 0.052726 & 0.000 & -1.30159 & -1.05841 \\
\hline & $30 \%$ & $-3.836000 *$ & 0.052726 & 0.000 & -3.95759 & -3.71441 \\
\hline \multirow{3}{*}{$5 \%$} & $0 \%$ & $0.294000 *$ & 0.052726 & 0.001 & 0.17241 & 0.41559 \\
\hline & $10 \%$ & $-0.886000 *$ & 0.052726 & 0.000 & -1.00759 & -0.76441 \\
\hline & $30 \%$ & $-3.542000 *$ & 0.052726 & 0.000 & -3.66359 & -3.42041 \\
\hline \multirow{3}{*}{$10 \%$} & $0 \%$ & $1.180000 *$ & 0.052726 & 0.000 & 1.05841 & 1.30159 \\
\hline & $5 \%$ & $0.886000 *$ & 0.052726 & 0.000 & 0.76441 & 1.00759 \\
\hline & $30 \%$ & $-2.656000 *$ & 0.052726 & 0.000 & -2.77759 & -2.53441 \\
\hline \multirow{3}{*}{$30 \%$} & $0 \%$ & $3.836000 *$ & 0.052726 & 0.000 & 3.71441 & 3.95759 \\
\hline & $5 \%$ & $3.542000 *$ & 0.052726 & 0.000 & 3.42041 & 3.66359 \\
\hline & $10 \%$ & $2.656000 *$ & 0.052726 & 0.000 & 2.53441 & 2.77759 \\
\hline
\end{tabular}

Note: * The significance level of the mean difference is 0.05 .

According to the results of the LSD analysis, it could be seen that the significance between the various asphalts was less than 0.05 , which indicates that the change of bio-oil content had a significant effect on the mass loss. 


\subsection{Temperature Sweep Test}

The temperature sweep tests of unaged and RTFO-aged matrix asphalts and bio-asphalt binders were carried out, and the complex modulus $G^{*}$, phase angle $\delta$, and rutting factor $G^{*} / \sin$ $\delta$ were analyzed.

As seen in Figure 7a,b, for unaged asphalt, the phase angle of bio-asphalts with 5\% and 10\% bio-oil content, and 10\%-S, gradually increased with the increase of temperature; this indicated that the viscous component increased with increasing temperature. However, the phase angle of 50\# matrix asphalt and $5 \%-S$ reached a maximum at $64{ }^{\circ} \mathrm{C}$, indicating that the viscous components also reached a maximum at that temperature. The phase angle of bio-asphalt with $30 \%$ content bio-oil had a smaller downward trend; this was due to the excessive variability of the bio-oil. Compared with $50 \#$ base asphalt, the phase angles of unaged bio-asphalt with 5\% and $10 \%$ bio-oil were both higher than the base asphalt, while the phase angle of bio-asphalt with 30\% bio-oil was lower than that of the base asphalt. This indicated that the viscous components of bio-asphalt increased with the increase of the $5 \%$ and $10 \%$ bio-oil content, and that the high-temperature performance was affected by the bio-oil. The bio-asphalt with $30 \%$ bio-oil content reduced; this was caused by the extreme variability of the $30 \%$ bio-oil. For the RTFO-aged asphalt, the phase angle of bio-asphalt increased with the increase of temperature, and the phase angles of bio-asphalt with $5 \%$ and $10 \%$ content bio-oil were lower than those of the matrix asphalt when the temperature was lower than $70{ }^{\circ} \mathrm{C}$, while they were higher when the temperature was greater than $70{ }^{\circ} \mathrm{C}$. This indicated that when the temperature was greater than $70{ }^{\circ} \mathrm{C}$, the incorporation of $5 \%$ and $10 \%$ of the bio-oil would increase the viscosity of the bio-asphalt. Meanwhile, the phase angle of the bio-asphalt with 30\% bio-oil content was higher than that of the matrix asphalt and of the bio-asphalts with $5 \%$ and $10 \%$ content bio-oil, indicating that it had a larger viscous component, and that it had lower high temperature performance. The phase angles of bio-asphalt 5\%-S and 10\%-S were lower than those of other bio-asphalts, due to the elasticity of SBS.

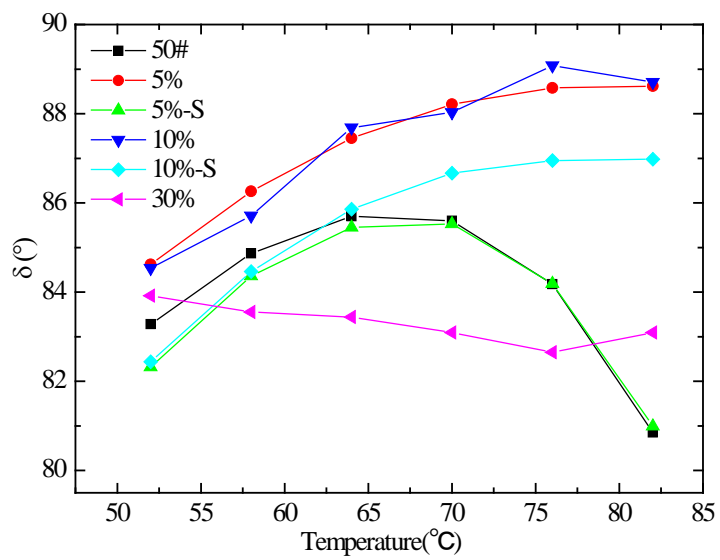

(a)

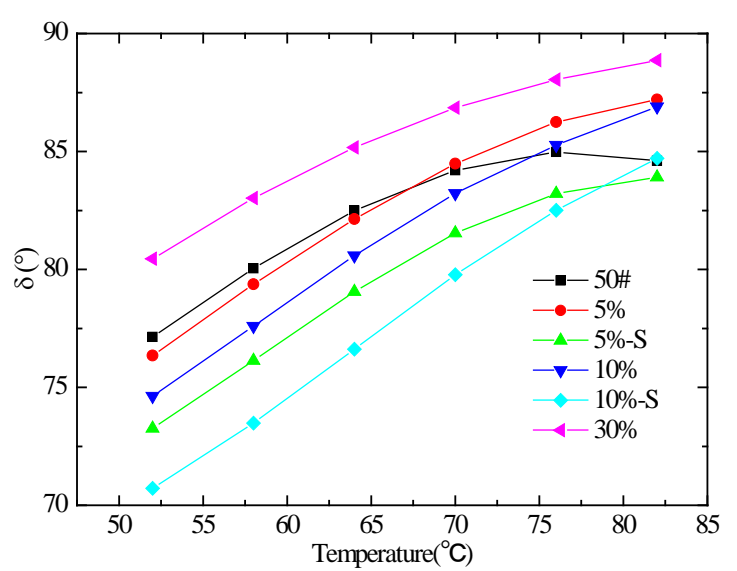

(b)

Figure 7. The relationship between phase angle and temperature. (a) Unaged; (b) RTFO aged.

As shown in Figure 8a,b, for the unaged and RTFO-aged asphalts, the complex modulus of bio-asphalt decreased with the increase of temperature; this indicated that, with the increase of temperature, the asphalt became soft, and its resistance to rutting declined. The sequence of complex modulus for the unaged and RTFO-aged asphalt were $G^{*}(50 \#)>G^{*}(5 \%)=G^{*}(10 \%)>G^{*}(30 \%), G^{*}$ $(30 \%)>G^{*}(10 \%)>G^{*}(5 \%)=G^{*}(50 \#)$, respectively. The results showed that the complex modulus of bio-asphalts without SBS decreased with an increase of bio-oil content. After short-term aging, the sequence was opposite to that of the unaged asphalt. This indicated that the bio-asphalt became softer with the addition of bio-oil for the unaged, and harder for the RTFO-aged; the results were consistent with those of the conventional tests. This was due to the aging of the bio-asphalt after the addition of 
significant quantities of bio-oil. The modulus of 5\%- and 10\%-S were improved more than those of the bio-asphalts with $5 \%$ and $10 \%$ bio-oil, but the action of SBS was different, based on the bio-oil content and RTFO aging.

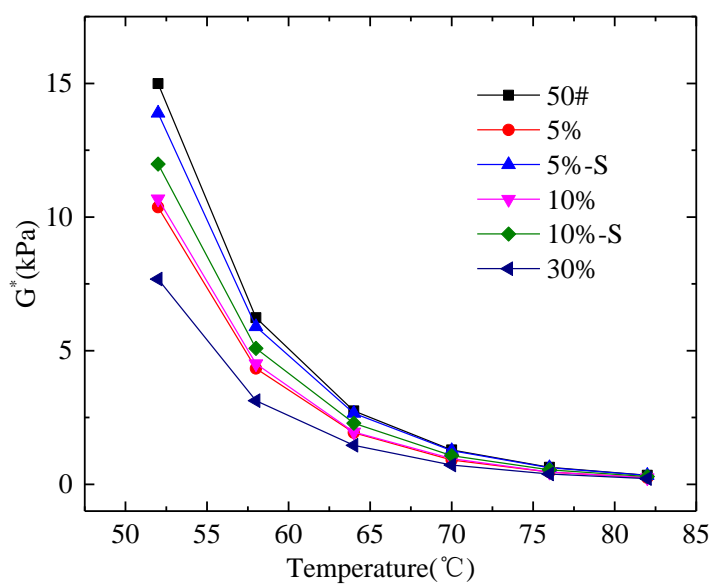

(a)

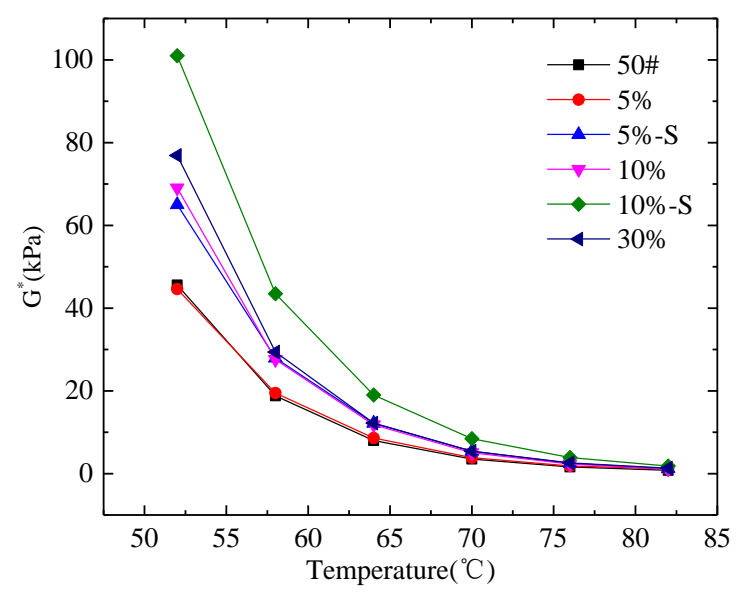

(b)

Figure 8. The relationship between complex modulus and temperature. (a) Unaged; (b) RTFO aged.

Figure 9a,b shows the relationship between rutting factors and temperature. The changes of the rutting factors of bio-asphalt and matrix asphalt were relatively consistent with the changes of complex modulus. The sequence of rutting factors for the unaged and RTFO-aged asphalts were $\mathrm{G}^{*} / \sin \delta(50 \#)>\mathrm{G}^{*} / \sin \delta(5 \%)=\mathrm{G}^{*} / \sin \delta(10 \%)>\mathrm{G}^{*} / \sin \delta(30 \%)$ and $\mathrm{G}^{*} / \sin \delta(30 \%)>\mathrm{G}^{*} / \sin \delta(10 \%)$ $>G^{*} / \sin \delta(5 \%)=G^{*} / \sin \delta(50 \#)$, respectively. The changes were also consistent with the changes of complex modulus. This was caused by the aging of bio-asphalt, especially for the bio-asphalt with $10 \%$ and $30 \%$ bio-oil content.

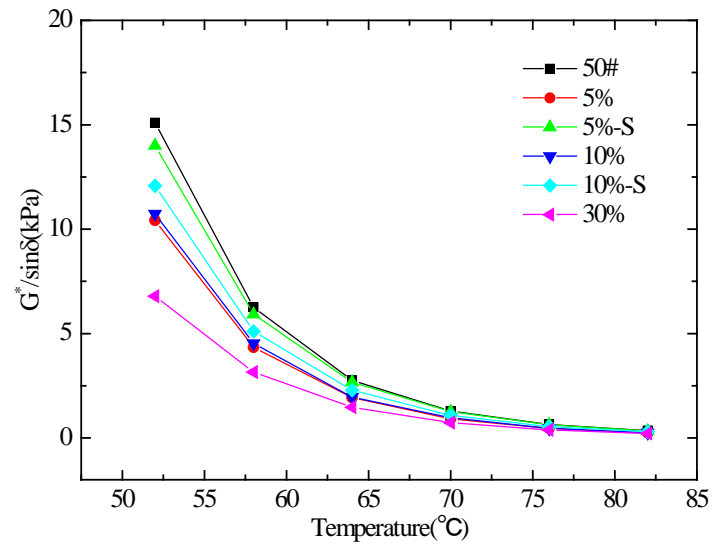

(a)

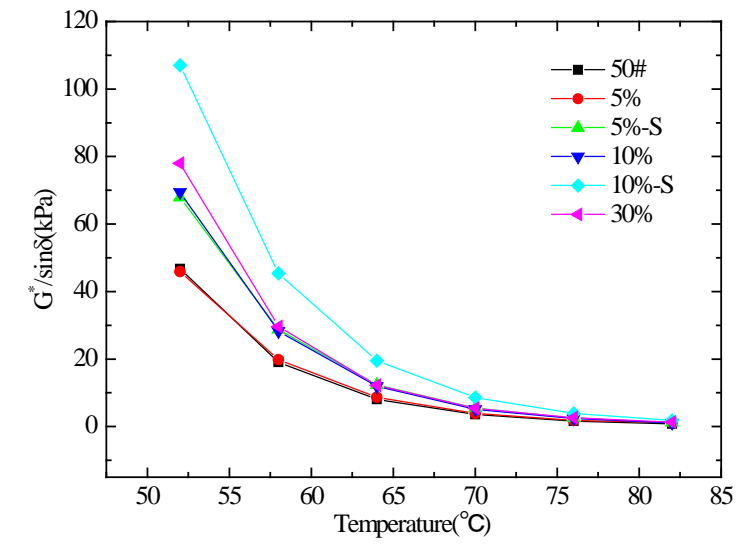

(b)

Figure 9. The relationship between rutting factors and temperature. (a) Unaged; (b) RTFO aged.

\subsection{Temperature Sensitivity Analysis}

Asphalt is a viscoelastic-plastic material whose properties are affected by temperature. In detail, the rutting factors decrease with an increase in temperature. The temperature sensitivity is defined as the gradient of the rutting factors when the temperature changes. In order to analyze the temperature sensitivity of bio-asphalt, a line was utilized to describe the relationship between $\ln \left(G^{*} / \sin (\delta)\right)$ and $\ln (\mathrm{T})$. A higher slope of the fitted line means that a higher temperature sensitivity of the asphalt is observed. 
Figure 10a,b shows the linear regression between $\ln \left(\mathrm{G}^{*} / \sin (\delta)\right)$ and $\ln (\mathrm{T})$. As can be seen in Figure $10, \ln \left(\mathrm{G}^{*} / \sin (\delta)\right)$ and $\ln (\mathrm{T})$ were linear, and the fitted formulas were obtained; they are shown in Tables 2 and 3.

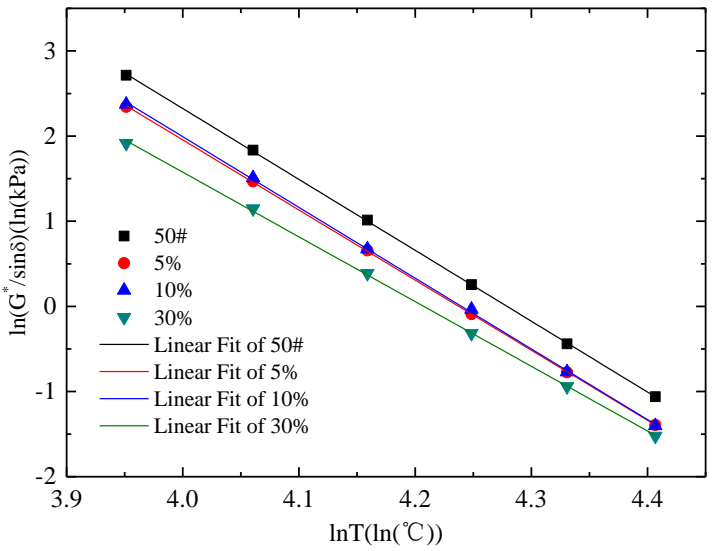

(a)

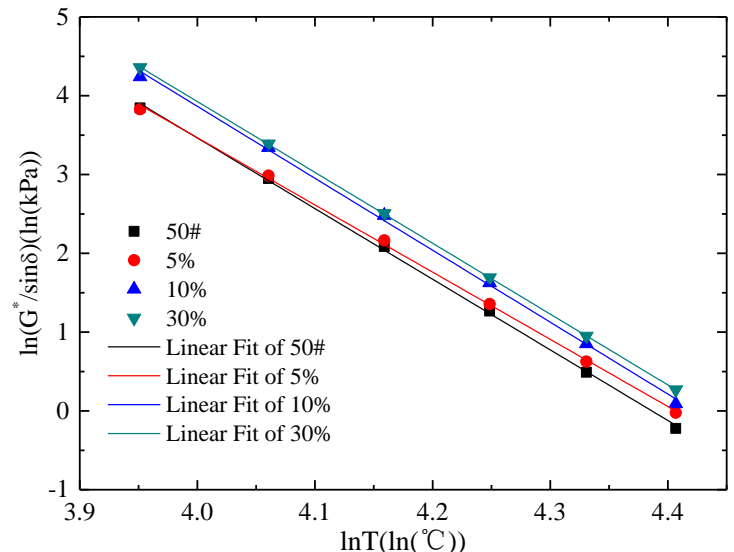

(b)

Figure 10. Linear regression between $\ln \left(\mathrm{G}^{*} / \sin \delta\right)$ and $\operatorname{lnT}$. (a) Unaged; (b) RTFO-aged.

Table 2. Linear fitting results of different asphalt temperature sweep data for the unaged asphalts.

\begin{tabular}{ccc}
\hline Asphalt Type & Equation & $\mathbf{R}^{\mathbf{2}}$ \\
\hline 50\#-base asphalt & $\ln \left(\mathrm{G}^{*} / \sin \delta\right)=-8.323 \ln T+35.616$ & 0.99991 \\
5\%-bio-asphalt & $\ln \left(\mathrm{G}^{*} / \sin \delta\right)=-8.230 \ln T+34.876$ & 0.99994 \\
10\%-bio-asphalt & $\ln \left(\mathrm{G}^{*} / \sin \delta\right)=-8.306 \ln T+35.218$ & 0.99964 \\
30\%-bio-asphalt & $\ln \left(\mathrm{G}^{*} / \sin \delta\right)=-7.598 \ln T+31.966$ & 0.99965 \\
\hline
\end{tabular}

Table 3. Linear fitting results of different asphalt temperature sweep data for the RTFO-aged asphalt.

\begin{tabular}{ccc}
\hline Asphalt Type & Equation & $\mathbf{R}^{\mathbf{2}}$ \\
\hline 50\#-base asphalt & $\ln \left(\mathrm{G}^{*} / \sin \delta\right)=-8.962 \ln T+39.312$ & 0.99907 \\
5\%-bio-asphalt & $\ln \left(\mathrm{G}^{*} / \sin \delta\right)=-8.526 \ln T+37.570$ & 0.99906 \\
10\%-bio-asphalt & $\ln \left(\mathrm{G}^{*} / \sin \delta\right)=-9.128 \ln \mathrm{T}+40.376$ & 0.99848 \\
30\%-bio-asphalt & $\ln \left(\mathrm{G}^{*} / \sin \delta\right)=-8.989 \ln \mathrm{T}+39.882$ & 0.99998 \\
\hline
\end{tabular}

Note: RTFO is short for Rolling Thin Film Oven.

As can be seen from Tables 2 and 3, all $R^{2}$ values were very close to 1 , indicating very good linear fitting. Thus, the rutting factor logarithm of the matrix asphalt and bio-asphalt had good linear correlation with the temperature logarithm. The linear correlation could be characterized by the Equation (2):

$$
\ln \left(\mathrm{G}^{*} / \sin \delta\right)=\mathrm{A} \ln \mathrm{T}+\mathrm{B}
$$

wherein, $\mathrm{A}<0, \mathrm{~B}>0$; $\mathrm{A}$ and $\mathrm{B}$ could indicate the temperature sensitivity. As such, they were regarded as temperature sensitivity parameters, and the smaller the value of $|\mathrm{A}|$, the lower the sensitivity of the asphalt to temperature.

Results could be drawn from Tables 2 and 3: the sequence of $|\mathrm{A}|$ for the unaged was $|\mathrm{A}|$ $(50 \#)>|\mathrm{A}|(10 \%)>|\mathrm{A}|(5 \%)>|\mathrm{A}|(30 \%)$, the sequence of $|\mathrm{A}|$ for the RTFO aged bio-asphalt was $|\mathrm{A}|(10 \%)>|\mathrm{A}|(30 \%)>|\mathrm{A}|(50 \#)>|\mathrm{A}|(5 \%)$. For the unaged asphalt, the sensitivity did not show regularity, but the temperature sensitivity of bio-asphalt was lower than that of matrix asphalts. Among them, the temperature sensitivity of bio-asphalt with 30\% content bio-oil was the lowest. For the RTFO-aged asphalt, the temperature sensitivity of bio-asphalt was not regular, but when the 
bio-oil content was higher than $10 \%$, the temperature sensitivity was higher than that of the matrix asphalt. The temperature sensitivity of RTFO-aged bio-asphalt with $5 \%$ content bio-oil was the lowest.

\subsection{Frequency Sweep Test}

The bio-asphalt with 5\% bio-oil and base asphalt were selected for the frequency sweep test, according to the results of conventional tests and the temperature sweep test. The changes of phase angle, storage modulus, loss modulus, and complex modulus with frequency for the unaged and RTFO-aged were analyzed.

Figure 11 shows the changes of phase angle, storage modulus, loss modulus, and complex modulus of unaged bio-asphalt with 5\% bio-oil content. As can be seen in Figure 11, for the unaged bio-asphalt with $5 \%$ content bio-oil, with the increase of frequency, the phase angle reduced gradually at the same temperature, while the storage modulus, loss modulus, and complex modulus all increased gradually. This indicated that the asphalt exhibited greater elastic properties as the frequency increased, while the phase angle and the storage modulus had a certain fluctuation at $76{ }^{\circ} \mathrm{C}$, which may be a measurement error caused by the increase in temperature. In the case of lower frequencies, the phase angle, storage modulus, loss modulus, and complex modulus varied greatly with the change of frequency. When the frequency was higher than $5 \mathrm{~Hz}$, the viscoelastic curve stabilized gradually. As the temperature increased, the phase angle increased gradually, and the storage modulus, loss modulus, and complex modulus decreased gradually and the viscosity component of the bio-asphalt increased; this was consistent with the results of the temperature sweep.

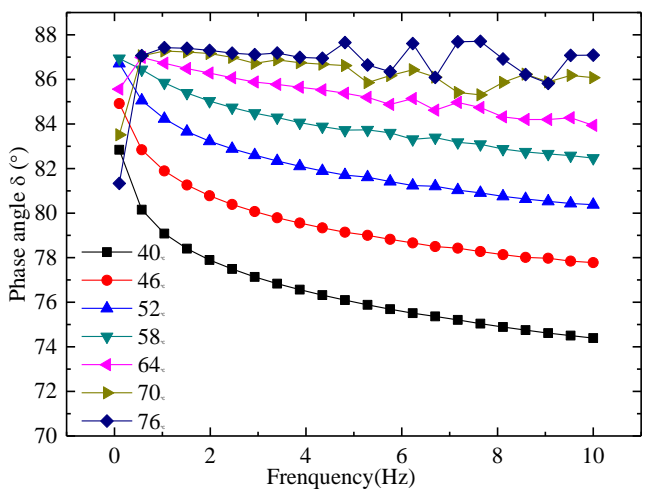

(a)

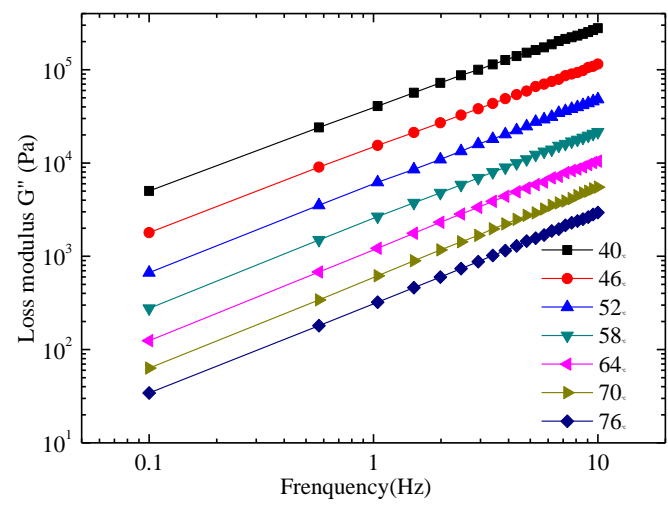

(c)

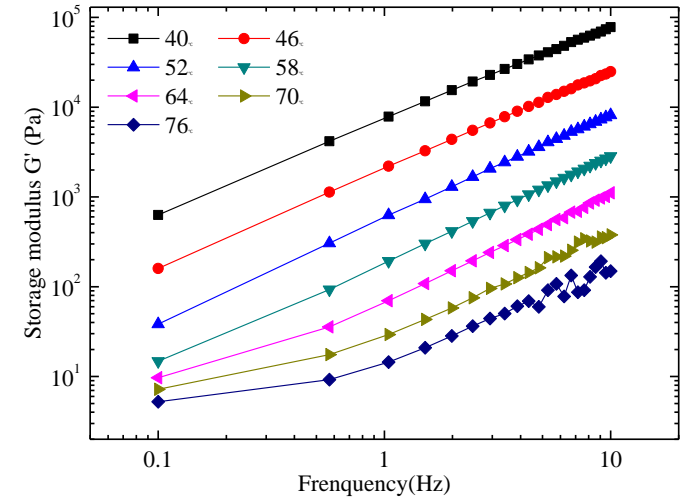

(b)

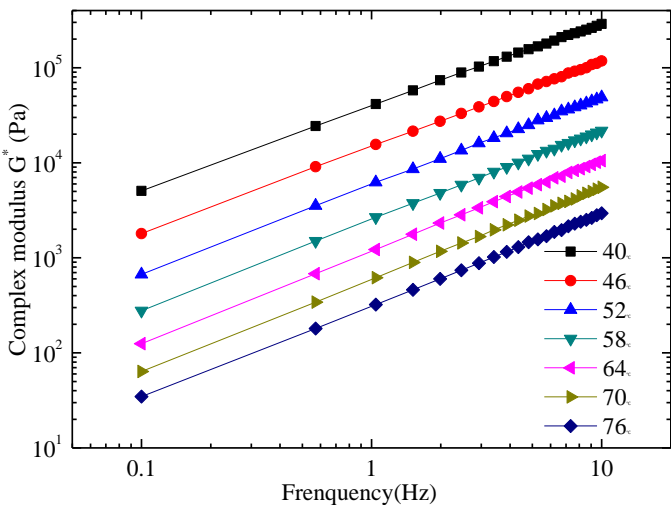

(d)

Figure 11. The changes of different parameters of unaged bio-asphalt with $5 \%$ content bio-oil. (a) Phase angle; (b) Storage modulus; (c) Loss modulus; (d) Complex modulus. 
Figure 12 shows the changes of phase angle, storage modulus, loss modulus, and complex modulus of RTFO-aged bio-asphalt with $5 \%$ content bio-oil. It can be seen that the changes of phase angle, storage modulus, loss modulus and complex modulus of asphalt were similar to those of the unaged asphalt.

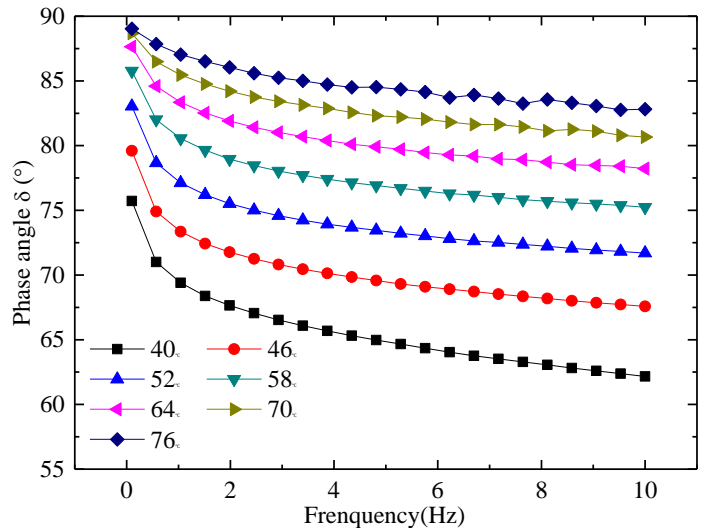

(a)

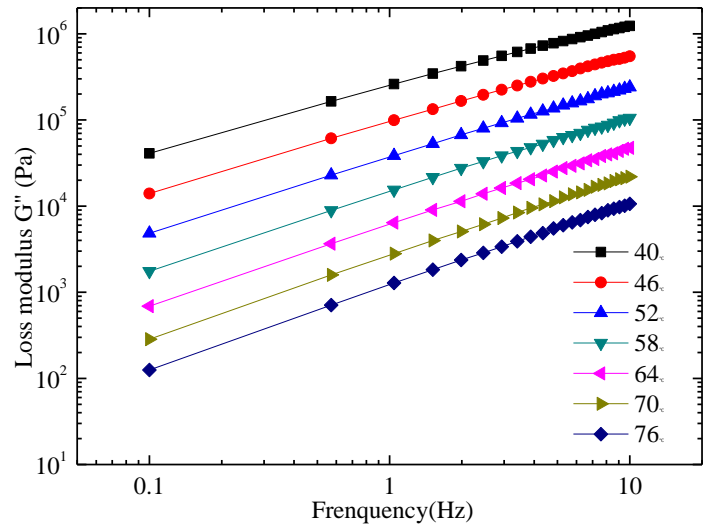

(c)

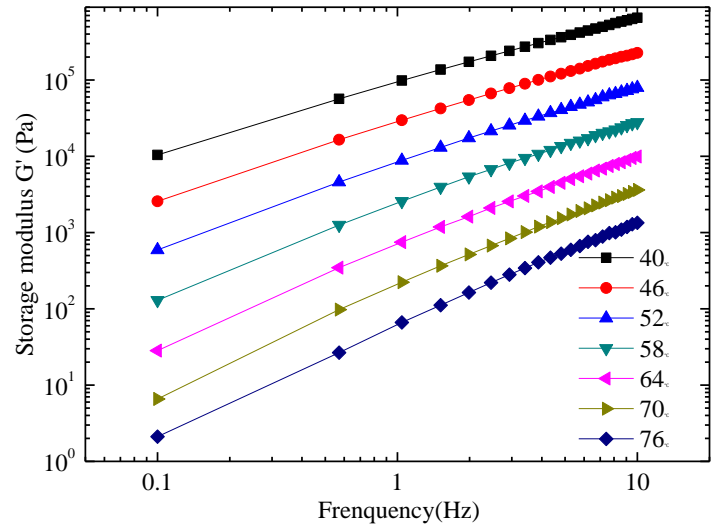

(b)

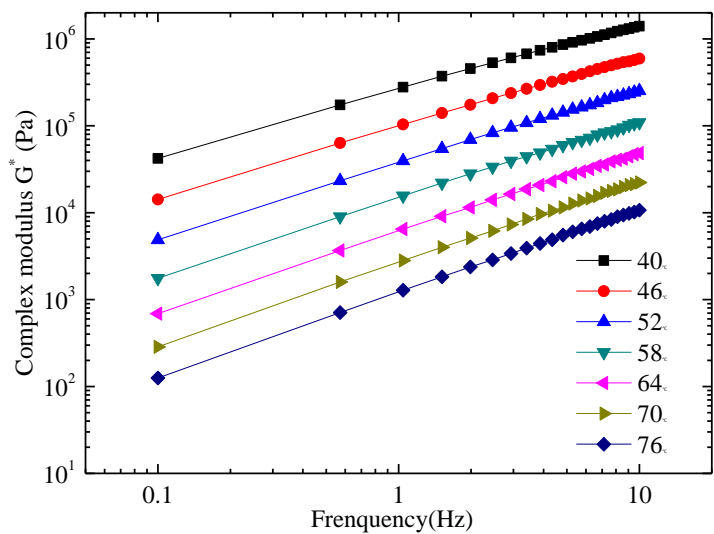

(d)

Figure 12. The changes of different parameters of RTFO-aged bio-asphalt with $5 \%$ bio-oil content. (a) Phase angle; (b) Storage modulus; (c) Loss modulus; (d) Complex modulus.

\subsection{Master Curve Generation}

The master curve of the complex modulus and the rutting factors of the base asphalt and the bio-asphalt with $5 \%$ bio-oil were generated in the broadband range using the time-temperature equivalent principle. The reference temperature was $64{ }^{\circ} \mathrm{C}$.

As seen in Figure 13a,b, unaged bio-asphalt with 5\% bio-oil content, and 50\# matrix asphalt, had a similar trend from a low to high-frequency range, and the complex modulus and rutting factors increased with the increase of frequency. In the lower frequency range, the complex modulus and rutting factors of unaged bio-asphalt with 5\% bio-oil were consistent with those of the $50 \#$ base asphalt, indicating that the bio-asphalt with 5\% bio-oil had the same resistance to rutting as the 50\# base asphalt. In the higher frequency range, the complex modulus and rutting factors of the unaged bio-asphalt with $5 \%$ bio-oil reduced to some extent, compared with $50 \#$ base asphalt, which indicated that it was superior to matrix asphalt in low-temperature, anti-cracking performance in the higher frequency range. 


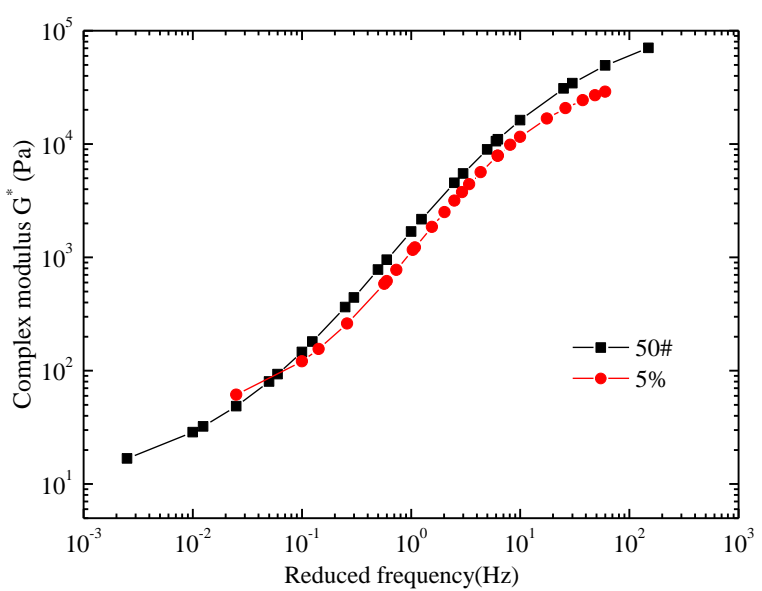

(a)

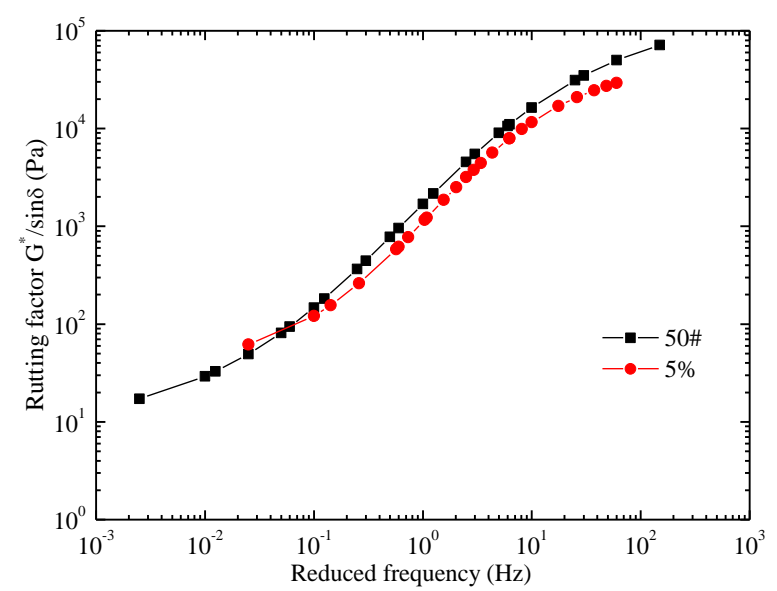

(b)

Figure 13. The changes of different parameters with reduced frequency change for the unaged asphalt. (a) Complex modulus; (b) Rutting factor.

As shown in Figure 14a,b, RTFO-aged bio-asphalt with 5\% content bio-oil and 50\# matrix asphalt had a similar trend from low to high frequency range, and the complex modulus and rutting factors increased as the frequency increased. In the lower frequency range, the complex modulus and rutting factors of RTFO-aged bio-asphalt with $5 \%$ bio-oil were larger than those of the 50\# base asphalt, which indicated that bio-asphalt had a better ability to resist rutting deformation. In the medium frequency range, the complex modulus and rutting factors of RTFO-aged bio-asphalt with 5\% bio-oil were similar to those of the 50\# matrix asphalt, and the anti-cracking performance of both was not much different. In the higher frequency range, the complex modulus and rutting factors of the RTFO-aged bio-asphalt with $5 \%$ bio-oil content were larger than those of the 50\# base asphalt, and its rutting resistance increased. This was because the performances of bio-asphalt after RTFO had been affected by the aging, although the impact was not significant.

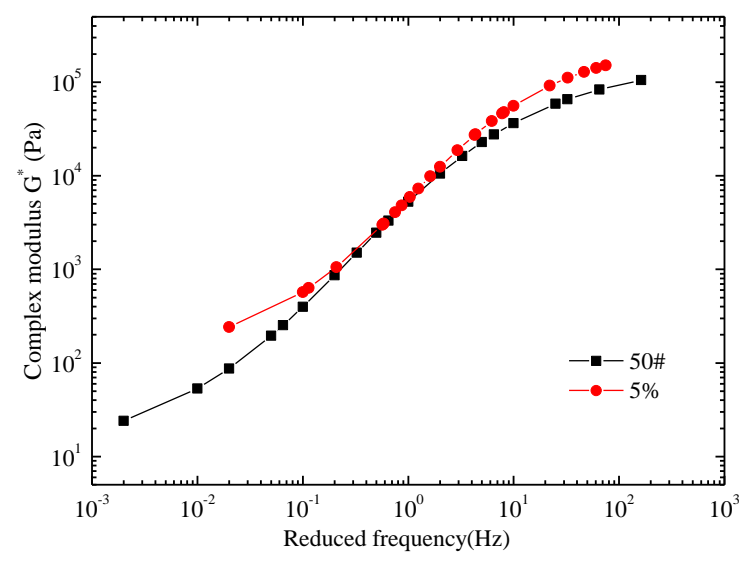

(a)

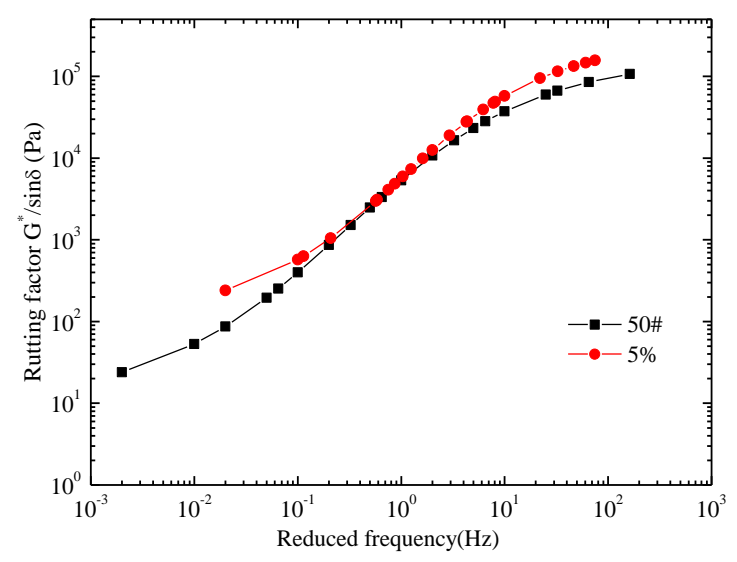

(b)

Figure 14. The changes of different parameters with reduced frequency change for the RTFO-aged asphalt. (a) Complex modulus; (b) Rutting factor.

\subsection{Functional Group Compositions Analysis}

In order to study the reaction mechanism and the changes of $50 \#$ base asphalt with bio-oil, the relative variations in the functional groups of 50\# base asphalt, bio-asphalt with $30 \%$ bio-oil, 
and the bio-oil were analyzed. As shown in Figure 15, FTIR spectra were constructed, showing the changes of absorbance spectra with wavenumber.

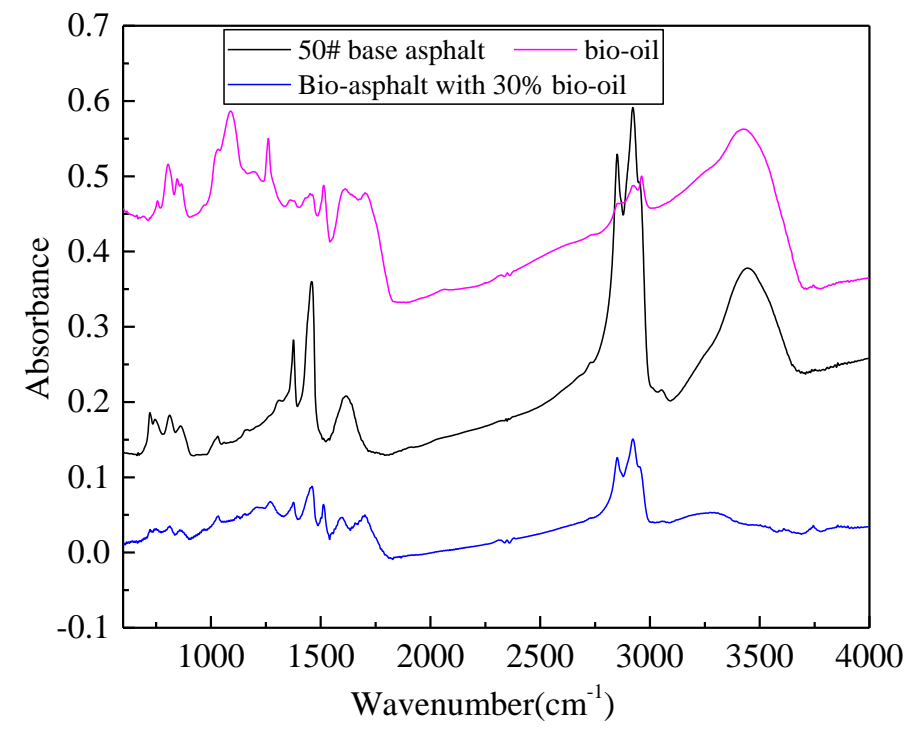

Figure 15. FTIR spectra of three kinds of binders.

The absorbance spectra trends of 50\# base asphalt, bio-oil, and 50\# base asphalt with $30 \%$ bio-oil were different. Based on the absorbance spectra peaks, the functional groups were analyzed from the three kinds of binders. The functional groups were identified and listed in Table 4.

Table 4. Functional groups identified of three kinds of binders.

\begin{tabular}{|c|c|c|c|}
\hline Binder Types & Absorption Wave Number & Functional Groups & Class of Compounds [22-24] \\
\hline \multirow{6}{*}{$50 \#$ base asphalt } & $788-842$ & C-H plane bending & Aromatic compounds \\
\hline & 1024 & $\mathrm{~S}=\mathrm{O}$ & Sulfoxide \\
\hline & 1379,1452 & $\mathrm{CH}_{3}$ & Aliphatic compounds \\
\hline & 1602 & $\mathrm{C}=\mathrm{C}$ ring stretch & Aromatic compounds \\
\hline & 2852,2925 & C-H stretching & Alkanes \\
\hline & 3421 & O-H stretching, N-H stretching & Polymeric $\mathrm{O}-\mathrm{H}$, water, $\mathrm{NH}_{2}$ \\
\hline \multirow{9}{*}{ Bio-oil } & $763-827$ & C-H plane bending & Aromatic compounds \\
\hline & 1097 & $\mathrm{~S}=\mathrm{O}$ & Sulfoxide \\
\hline & 1263 & C-O stretching & Phenol, esters \\
\hline & 1379,1452 & $\mathrm{CH}_{3}$ & Aliphatic compounds \\
\hline & 1519 & $-\mathrm{NO}_{2}$ stretching & Nitrogenous compounds \\
\hline & 1602 & $\mathrm{C}=\mathrm{C}$ ring stretch & Aromatic compounds \\
\hline & 1706 & $\mathrm{C}=\mathrm{O}$ stretching & Ketones, aldehydes, carboxylic acids \\
\hline & 2852,2924 & C-H stretching & Alkanes \\
\hline & 3421 & O-H stretching, N-H stretching & Polymeric $\mathrm{O}-\mathrm{H}$, water, $\mathrm{NH}_{2}$ \\
\hline \multirow{8}{*}{$\begin{array}{l}\text { Bio-asphalt (50\# } \\
\text { base asphalt with } \\
30 \% \text { bio-oil) }\end{array}$} & $769-839$ & C-H plane bending & Aromatic compounds \\
\hline & 1024 & $\mathrm{~S}=\mathrm{O}$ & Sulfoxide \\
\hline & 1379,1452 & $\mathrm{CH}_{3}$ & Aliphatic compounds \\
\hline & 1519 & $-\mathrm{NO}_{2}$ stretching & Nitrogenous compounds \\
\hline & 1602 & $\mathrm{C}=\mathrm{C}$ ring stretch & Aromatic compounds \\
\hline & 1706 & $\mathrm{C}=\mathrm{O}$ stretching & Ketones, aldehydes, carboxylic acids \\
\hline & 2852,2952 & C-H stretching & Alkanes \\
\hline & 3307 & $\mathrm{O}-\mathrm{H}$ stretching, $\mathrm{N}-\mathrm{H}$ stretching & Polymeric $\mathrm{O}-\mathrm{H}$, water, $\mathrm{NH}_{2}$ \\
\hline
\end{tabular}

As shown in Figure 15 and Table 4, there was an obvious difference between 50\# base asphalt and bio-oil. For the 50\# base asphalt, $\mathrm{C}-\mathrm{H}$ bending was dominant, while bio-oil had a large amount of different functional groups, such as $\mathrm{O}-\mathrm{H}$ stretching, $\mathrm{S}=\mathrm{O}, \mathrm{C}=\mathrm{O}$ stretching, and $\mathrm{C}-\mathrm{O}$ stretching. This was mainly attributed to a great deal of oxygen in the bio-oil; it contributes to the aging process of bio-oil and bio-asphalt with bio-oil [22]. 
From the comparison of the three kinds of binders, it can be seen that there was an obvious peak with wavenumber $1263 \mathrm{~cm}^{-1}$, representing the presence of esters and phenol in the bio-oil. However, this disappeared after the bio-oil was added to 50\# base asphalt. The peaks at $3421 \mathrm{~cm}^{-1}$ in bio-oil and 50\# base asphalt disappeared in the bio-asphalt, and a new peak at $3307 \mathrm{~cm}^{-1}$ appeared in the bio-asphalt. These illustrated that some chemical reactions occurred when the 50\# base asphalt was mixed with bio-oil.

In addition, there are many different types of functional groups and compounds in the bio-oil and bio-asphalt, such as aldehydes, ketones, carboxylic acids, and phenol. Different compounds yielded different characteristics of the bio-asphalts with added bio-oil, as compared to conventional asphalt made from crude oil.

\section{Conclusions}

This research comprehensively investigated the high-temperature performances of bio-asphalt binders. Bio-asphalts with different contents of bio-oil extracted from wood chips were prepared. Conventional performance indexes of bio-asphalt binder were tested. The temperature sweep test and frequency sweep test of bio-asphalt with different bio-oil contents were carried out, and the temperature sensitivity of the bio-asphalt was analyzed. The master curves of matrix asphalt and bio-asphalt were constructed, and the changes of complex modulus and rutting factors of bio-asphalt under different frequencies were studied. Based on this study, the following conclusions were obtained:

(1) With an increase of bio-oil content, penetration and ductility of unaged bio-asphalt increased gradually; the anti-cracking performance increased slightly; the softening point decreased, while the anti-rutting ability of unaged bio-asphalt decreased. For the RTFO-aged asphalt, the residual penetration ratio and the softening point difference were large, indicating that the bio-asphalt underwent a certain degree of aging after heating. The content of bio-oil had a significant effect on the mass loss of the bio-asphalt.

(2) For the unaged and RTFO-aged bio-asphalts with 5\% bio-oil, 5\%-S, and 10\%-S, the results indicated that the penetration, softening point, ductility, residual penetration ratio, mass loss, and other indicators, could meet the requirements of $50 \#$ grade asphalt.

(3) The phase angle, complex modulus, and rutting factors decreased gradually with the increase of temperature for the unaged and RTFO-aged asphalts, which indicated that the high-temperature performances of bio-asphalt decreased with increasing temperature. The sequence of the phase angle, complex modulus, and rutting factors with different contents of bio-oil showed different changes, which were caused by the aging of the bio-oil.

(4) The temperature sensitivity of both the unaged and RTFO-aged asphalts did not display regularity. The temperature sensitivity of unaged bio-asphalt was lower than that of the matrix asphalt. When the bio-oil content was higher than $10 \%$, the temperature sensitivity of RTFO-aged bio-asphalt was higher than that of the matrix asphalt. The temperature sensitivity of RTFO-aged bio-asphalt with $5 \%$ content bio-oil was the smallest.

(5) According to the frequency sweep test, the phase angle, storage modulus, loss modulus, and complex modulus of the unaged and RTFO-aged bio-asphalts and the matrix asphalt changed greatly with the change of frequency, at the lower frequency. When the frequency was greater than $5 \mathrm{~Hz}$, the viscoelastic curve stabilized gradually. As the temperature increased, the phase angle increased gradually, and the storage modulus, the loss modulus, and the complex modulus decreased gradually, while the viscous component of the bio-asphalt increased. This was consistent with the results of the temperature sweep.

(6) According to the mater curve analysis, the complex modulus and rutting factors of bio-asphalt with 5\% content bio-oil and 50\# matrix asphalt increased with the increase of frequency, from the low frequency to the high-frequency range. Unaged bio-asphalt with $5 \%$ bio-oil content in the lower frequency range had considerable rutting resistance compared to the matrix 
asphalt. In contrast, at the higher frequency range, the complex modulus and rutting factors of bio-asphalt with $5 \%$ bio-oil were lower than those of the 50\# base asphalt, which was superior to matrix asphalt in low-temperature anti-cracking performance. The RTFO-aged bio-asphalt with $5 \%$ bio-oil had a higher resistance to rutting than the matrix asphalt at the low and high-frequency ranges.

(7) Chemical reactions occurred when the 50\# base asphalt was mixed with bio-oil.

Author Contributions: J.G. and H.W. conceived and designed the experiments; J.G. performed the experiments; J.G. and H.W. analyzed the data; H.W. and Z.Y. contributed reagents /materials; J.G. wrote the paper; M.R.M.H., Y.L. and M.I. reviewed and edited the paper.

Acknowledgments: This research is sponsored by National Natural Science Foundation of China (No. 51578075, 51778062), the Fundamental Research Foundation of the Central Universities (No. 300102218718) and the Fundamental and Applied Research Project of the Chinese National Transportation Department (No. 2014319812180). The authors also gratefully acknowledge the financial support from China Scholarship Council (No. 201706560009).

Conflicts of Interest: The authors declare no conflict of interest.

\section{References}

1. Bostancioğlu, M.; Oruç, Ş. Effect of furfural-derived thermoset furan resin on the high-temperature performance of bitumen. Road Mater. Pavement Des. 2014, 16, 227-237. [CrossRef]

2. Cavaca, L.A.S.; Afonso, C.A.M. Oleuropein: A Valuable Bio-Renewable Synthetic Building Block. Eur. J. Org. Chem. 2018, 2018, 581-589. [CrossRef]

3. Pereira, P.; Pais, J. Main flexible pavement and mix design methods in Europe and challenges for the development of an European method. J. Traffic Transp. Eng. Engl. Ed. 2017, 4, 316-346. [CrossRef]

4. Mohammad, L.; Elseifi, M.; Cooper, S.; Challa, H.; Naidoo, P. Laboratory Evaluation of Asphalt Mixtures That Contain Biobinder Technologies. Transp. Res. Rec. J. Transp. Res. Board 2013, 2371, 58-65. [CrossRef]

5. Cuadri, A.A.; García-Morales, M.; Navarro, F.J.; Partal, P. Processing of bitumens modified by a bio-oil-derived polyurethane. Fuel 2014, 118, 83-90. [CrossRef]

6. Yang, X.; You, Z.; Dai, Q. Performance evaluation of asphalt binder modified by bio-oil generated from waste wood resources. Int. J. Pavement Res. Technol. 2013, 6, 431-439.

7. Fini, E.H.; Al-Qadi, I.L.; You, Z.; Zada, B.; Mills-Beale, J. Partial replacement of asphalt binder with bio-binder: Characterisation and modification. Int. J. Pavement Eng. 2012, 13, 515-522. [CrossRef]

8. Fini, E.H.; Hosseinnezhad, S.; Oldham, D.J.; Chailleux, E.; Gaudefroy, V. Source dependency of rheological and surface characteristics of bio-modified asphalts. Road Mater. Pavement Des. 2016, 18, 408-424. [CrossRef]

9. Fini, E.H.; Kalberer, E.W.; Shahbazi, A.; Basti, M.; You, Z.; Ozer, H.; Aurangzeb, Q. Chemical Characterization of Biobinder from Swine Manure: Sustainable Modifier for Asphalt Binder. J. Mater. Civ. Eng. 2011, 23, 1506-1513. [CrossRef]

10. Fini, E.H.; Oldham, D.J.; Abu-Lebdeh, T. Synthesis and Characterization of Biomodified Rubber Asphalt: Sustainable Waste Management Solution for Scrap Tire and Swine Manure. J. Environ. Eng. 2013, 139, 1454-1461. [CrossRef]

11. Fini, E.H.; Yang, S.-H.; Xiu, S. Characterization and Application of Manure-Based Bio-binder in Asphalt Industry. Transp. Res. Board 2010, 2010, 10-2871.

12. Mills-Beale, J.; You, Z.; Fini, E.; Zada, B.; Lee, C.H.; Yap, Y.K. Aging Influence on Rheology Properties of Petroleum-Based Asphalt Modified with Biobinder. J. Mater. Civ. Eng. 2014, 26, 358-366. [CrossRef]

13. Raouf, M.; Williams, R. Temperature and Shear Susceptibility of a Nonpetroleum Binder as a Pavement Material. Transp. Res. Rec. J. Transp. Res. Board 2010, 2180, 9-18. [CrossRef]

14. Raouf, M.A.; Williams, R.C. Determination of Pre-Treatment Procedure Required for Developing Bio-Binders from Bio-Oils. In Proceedings of the 2009 Mid-Continent Transportation Research Symposium, Ames, IA, USA, 20-21 August 2009.

15. Tang, S.; Williams, R.C. Antioxidant Effect of Bio-Oil Additive ESP on Asphalt Binder. In Proceedings of the 2009 Mid-Continent Transportation Research Symposium, Ames, IA, USA, 20-21 August 2009. 
16. Yang, S.H.; Suciptan, T. Rheological behavior of Japanese cedar-based biobinder as partial replacement for bituminous binder. Constr. Build. Mater. 2016, 114, 127-133. [CrossRef]

17. Wang, H.; Gao, J.; You, Z.; Tian, Y. Advances in bio-binder application on road pavement. J. Wu Han Univ. Technol. 2014, 36, 57-60. (In Chinese)

18. Gao, J.; Wang, H.; You, Z.; Yang, X. Gray relational entropy analysis of high temperature performance of bio-asphalt binder and its mixture. Int. J. Pavement Res. Technol. 2018. [CrossRef]

19. Wang, H.; Gao, J.; Zhao, X.; You, Z.; Tian, Y. Rheological Properties on Bio-binder based on DSR and RV. J. Hu Nan Univ. Nat. Sci. 2015, 42, 26-33. (In Chinese)

20. He, M.; Cao, D.; Zhang, H.; Song, Z.; Wu, X. Research on Conventional Performance of Modified Bio-Asphalt. J. Highw. Transp. Res. Dev. Engl. Ed. 2015, 9, 1-6. [CrossRef]

21. Gao, J.; Wang, H.; You, Z.; Hasan, M.R.M. Research on properties of bio-asphalt binders based on time and frequency sweep test. Constr. Build. Mater. 2018, 160, 786-793. [CrossRef]

22. Zhang, R.; Wang, H.; Jiang, X.; You, Z.; Yang, X.; Ye, M. Thermal Storage Stability of Bio-Oil Modified Asphalt. J. Mater. Civ. Eng. 2018, 30, 04018054. [CrossRef]

23. Li, H.; Xia, S.; Li, Y.; Ma, P.; Zhao, C. Stability evaluation of fast pyrolysis oil from rice straw. Chem. Eng. Sci. 2015, 135, 258-265. [CrossRef]

24. Alsbou, E.; Helleur, B. Accelerated Aging of Bio-oil from Fast Pyrolysis of Hardwood. Energy Fuels 2014, 28, 3224-3235. [CrossRef]

(C) 2018 by the authors. Licensee MDPI, Basel, Switzerland. This article is an open access article distributed under the terms and conditions of the Creative Commons Attribution (CC BY) license (http:/ / creativecommons.org/licenses/by/4.0/). 